ARS Cristian Borges*

ano 17

n. 36

\title{
Sobre a noção de três espaços no cinema.
}

Artigo inédito

palavras-chave:

espaço pictórico; espaço arquitetônico; espaço fílmico;

Éric Rohmer; Fausto keywords:

pictorial space; architectural

space; filmic space; Éric

Rohmer; Faust
*Universidade de São Paulo

(USP), Brasil.

DOI: 10.11606/issn.2178-0447. ars.2019.159116
Em sua tese de doutorado sobre o filme Fausto (1926), do alemão F. W. Murnau, o cineasta francês Éric Rohmer identifica no cinema, ou pelo menos no tipo de cinema mais convencional e narrativo que lhe interessa, três aspectos do espaço que ele denomina: pictórico, arquitetônico e fílmico. Como veremos, se essa divisão pode, por um lado, servir a uma função didática ligada ao aprendizado sobre a composição visual das imagens fílmicas, ela se revela, por outro lado, reducionista e artificial ao ignorar, ou ao menos desprezar, a componente temporal do cinema em favor de sua faceta espacial.

In his doctoral thesis on F. W. Murnau's film Faust (1926), French filmmaker Éric Rohmer identifies in cinema, or at least in the most conventional and narrative type of cinema that interests him, three aspects of cinematic space he calls: pictorial, architectural and filmic. As we shall see, if this division can, on the one hand, serve a didactic function linked to learning about the visual composition of filmic images, it is, on the other hand, a reductionist and artificial one by ignoring, or at least disregarding, the temporal component of the cinema in favor of its spatial facet. 
0 espaço pictórico

O cineasta francês Éric Rohmer (1920-2010), em um artigo da série intitulada "O celuloide e o mármore" ("Le celluloïd et le marbre"), publicada na revista Cahiers du cinéma em 1955, retoma uma ideia já proposta alguns anos antes em um outro artigo, publicado em 1948, sob o pseudônimo Maurice Schérer"1: "o cinema é uma arte do espaço: isso não prova que ele deva buscar auxílio neste ramo particular das artes da forma que é a pintura, tal como a concebemos desde a Renascença”" ${ }^{2}$ Porém, em sua tese de doutorado, defendida em 1972 e intitulada A organização do espaço no Fausto de Murnau, ele define três tipos de espaço no cinema, dos quais o primeiro é justamente o que ele nomeia pictórico ${ }^{3}$.

A aplicação do termo pictórico - que evidentemente remete à pintura, parecendo portanto estrangeiro ao cinema enquanto arte autônoma - remonta aos primeiros anos de existência do cinema. Como Pierre Sorlin ressalta, um crítico americano do início do século XX já tinha por hábito falar do cinema de um ponto de vista estritamente pictórico, daí o emprego em inglês do termo pictures ou moving pictures para designar os filmes ou a indústria cinematográfica: "Johnson avaliava os filmes 'from a pictorial point of view', 'pictorially', e admirava Griffith, cuja 'composição é a de um pintor"' mento e aos diferentes elementos plásticos abordados em sua relação com a pintura - a iluminação, o desenho e as formas -, essa noção de "espaço pictórico" é desenvolvida por Rohmer logo na primeira parte de sua tese, a fim de demonstrar como alguns "raros cineastas", tais como Murnau, Eisenstein e Dreyer - manifestando, segundo ele, "uma real e profunda cultura pictórica" e "cuja concepção fotográfica deve mais à pintura dos museus que ao imaginário popular" -, fazem "obra de pintor" . Parece-nos que Bresson, ele mesmo pintor, dedica uma atenção especial a esse tipo de espaço em seus filmes ${ }^{6}$ - a despeito das discordâncias que possamos encontrar entre a ideia e prática do cinematógrafo e o raciocínio que Rohmer elabora a partir do estilo cinematográfico de Murnau.

André Bazin destaca, em seu artigo sobre a relação entre cinema e pintura, que, em um filme sobre pintura, "o quadro se encontra afetado pelas propriedades espaciais do cinema", pois "a tela de cinema destrói radicalmente o espaço pictórico"”. Ao inverter essa fórmula, pode-se deduzir que aplicar a pintura ao cinema - como deseja, de certo modo, Rohmer - equivale a fazer com que o filme seja afetado pelas propriedades espaciais da pintura? A teoria de Rohmer apoia-se, em princípio,

\section{Cristian Borges}

Sobre a noção de três espaços

no cinema

1. SCHÉRER, Maurice. Le cinéma, art de l'espace. La Revue du cinéma, Paris, n. 14, p. 3-13, jun. 1948. Retomado em: ROHMER, Éric. Le Goût de la beauté. Paris: Cahiers du cinéma: Éd. de l'Étoile, 1984. p. 27-35, tradução minha.

2. ROHMER, Éric. Le celluloïd et le marbre II: le siècle des peintres. Cahiers du cinéma, Paris, n. 49, p. 10-15, jul. 1955a. p. 10, tradução minha.

3. Tese defendida na Sorbonne em 1972: ROHMER, Éric.

L'Organisation de l'espace dans le Faust de Murnau. Paris: UGE, 1991.

4. SORLIN, Pierre. Esthétiques de l'audiovisuel. Paris: Nathan, 1992. p. 58, tradução minha.

5. ROHMER, 1991, p. 15-16, tradução minha.

6. Ao afirmar, por exemplo: "Tenha o olho do pintor. 0 pintor cria olhando"; e na mesma p. 102: "0 olho do pintor é um tiro que desloca o real. Em seguida, o pintor o remonta e o organiza nesse mesmo olho, segundo seu gosto, seus métodos, seu ideal de beleza". Ou ainda, na p. 98: "Eu sonhei com meu filme se fazendo pouco a pouco sob o olhar, como uma tela de pintor eternamente fresca". Cf. BRESSON, Robert. Notas sobre o cinematógrafo. São Paulo: Iluminuras, 2005.

7. BAZIN, André. Pintura e cinema. In: BAZIN, André.

0 que é o cinema? São Paulo: Cosac Naify, 2014. p. 206-207. 
no fato de que um fotograma qualquer extraído e isolado do filme de

ano 17

n. 36

8. ROHMER, 1991, p. 16-17, tradução minha: "Peguemos no Fausto, ao acaso, um fotograma, uma 'imagem". Ainda que façamos abstração do movimento que a anima (...) é inegável que ela 'se sustenta'. Não há nela um único ponto, uma única linha, uma única superfície, um único contraste de sombra e luz que não pareça, longe dos acasos da reprodução mecânica, traçada com a mesma liberdade, rigor ou fantasia que pela mão do homem".

9. Aliás, uma tendência que Luís Buñuel, segundo reza a lenda, conduzirá a uma busca por uma imagem "feia" na companhia do diretor de fotografia Gabriel Figueroa, em sua fase mexicana.

10. ROHMER, 1991, p. 17, tradução e grifos meus.

11. Ibidem, loc. cit., tradução minha.

12. Cf. Ibidem, p. 25, tradução minha: "esta capacidade que temos dificuldade de distinguir num cineasta".

13. Ibidem, p. 30, tradução minha. Murnau, ainda que destituído de seu movimento, "sustenta-se", mantendo-se forte e belo como um quadro ${ }^{8}$. O que contraria, de certo modo, a tendência bressoniana, que busca tornar as imagens cinematográficas "insignificantes". Contudo, Rohmer acaba suavizando sua proposta: no cinema de Murnau - em oposição à maior parte dos filmes feitos em estúdio, em condições similares e na mesma época -, o que conta não é "sua habilidade em dar a ilusão de pintura", mas antes a de "conservar o poder de investigação bruto, fotográfico, da câmera para nos fazer entrar plenamente num universo essencialmente pictórico. Melhor ainda, ele nos revela que o universo, nosso mundo cotidiano, é pictórico em sua natureza profunda" ${ }^{10}$.

Quando fala de fotografia em sua tese, Rohmer refere-se, antes de tudo, ao sentido cinematográfico do termo, ou seja, à "técnica" empregada no cinema concernente aos registros de imagens sobre a película - o que a língua inglesa denomina cinematography. Ele atribui, assim, o sucesso desse caráter "pictórico" - e, logo, "cinematográfico" - na obra de Murnau, num primeiro momento, a uma subordinação da forma à luz. Pois é a luz, para Rohmer, que "modela a forma, esculpindo-a" ${ }^{11}$. Não esqueçamos, no entanto, que o objeto de sua análise - o filme de Murnau, em seu estilo e sua construção, mas sobretudo em termos de espaço - pertence a um momento ou, se preferirmos, a uma escola (conhecida como Expressionismo Alemão) na qual os efeitos de iluminação e os fortes contrastes de claro/escuro encontram-se na ordem do dia.

Um segundo componente desse caráter pictórico do espaço no cinema, segundo Rohmer, diz respeito ao que ele denomina desenho. No caso de Murnau, o desenho estaria ligado a uma "determinada amplitude, uma plenitude do traço que pertence somente a ele, tornando-o facilmente identificável”, e que ele associa a uma predominância de tomadas em plano médio, desdenhando das "opções extremas", como o primeiro plano ou os planos de multidões - caros, por exemplo, a Fritz Lang. Além da "singularidade da iluminação" e da "particularidade do ponto de vista", Rohmer destaca como ponto crucial do que ele chama de desenho ${ }^{12}$, no cinema de Murnau, a "escolha de um motivo em movimento", pois "é sobretudo o movimento, em sua obra, que faz o desenho. É o movimento que ele trata de deformar, de interpretar em lugar de sua mão ausente" ${ }^{13}$. Enquanto o desenho, como segundo componente do espaço pictórico, é considerado por Rohmer como a maneira pela qual um cineasta contamina um filme com seu traço pessoal, o 
terceiro componente, as formas, representaria sobretudo a matéria pela qual ele opera, no sentido de que

o conteúdo anedótico dessas formas, seu impacto sentimental, as informações que elas transmitem, enquanto signos ou símbolos, são aí temas não desprezíveis, mas acessórios em relação ao jogo "puro" de formas no espaço, sobre o qual repousa o fascínio que exerce sobre nós toda criação de ordem plástica. ${ }^{14}$

Curiosamente, um conterrâneo e contemporâneo de Murnau, oriundo das artes plásticas e, até por isso, voltado a um cinema de vanguarda nada narrativo e muito experimental em termos de estruturas e formas, Hans Richter - associado ao chamado Cinema Absoluto alemão dos anos 1920, que congregava, além dele, Walter Ruttmann, Oskar Fischinger e o sueco Viking Eggeling -, argumenta, em artigo publicado em janeiro de 1955, no primeiro número da revista americana Film Reader, que o "principal problema estético do cinema" refere-se ao fato de ele servir mais para registrar outras conquistas criativas (da literatura, do teatro, da própria natureza: atores, peças, paisagens) do que para criar sensações propriamente fílmicas - em outras palavras: "em que medida a câmera (o filme, a cor, o som etc.) é desenvolvida e usada para reproduzir (qualquer objeto que apareça diante da objetiva) em vez de produzir (sensações impossíveis de serem suscitadas por qualquer outro meio)?” ${ }^{15}$. Para ele, a verdadeira vocação do cinema deveria consistir em outras ações, tais como:

a orquestração do movimento em ritmos visuais - a expressão plástica de um objeto em movimento sob condições variáveis de luz (...) -, a distorção e dissecação de um movimento, objeto ou forma e sua reconstrução em termos fílmicos (assim como os cubistas dissecavam e reconstruíam em termos pictóricos), a desnaturalização do objeto em uma forma qualquer a fim de recriá-lo cinematograficamente com a luz - a luz sendo tomada em sua transparência e volatilidade como uma matéria poética, dramática e construtiva -, o uso das qualidades mágicas do filme para criar o estado original do sonho - a completa liberação da história convencional com sua cronologia em desenvolvimentos dadaístas e surrealistas nos quais o objeto é retirado de seu contexto habitual e posto em novas relações, gerando assim um conteúdo absolutamente novo. ${ }^{16}$

Percebemos, nessa reivindicação de Richter de uma "narratividade plástica" própria ao cinema, algo daquilo que Rohmer sugere como sendo, no filme de Murnau, uma "dramaturgia das formas puras".

\section{Cristian Borges}

Sobre a noção de três espaços

no cinema

14. Ibidem, p. 34, tradução minha. E ele completa: "assim como em um filme de Murnau correm paralelamente dois tipos de temas: uma organização, uma dramaturgia das formas puras e, ao mesmo tempo, um drama no sentido corrente do termo, uma temática, uma problemática". Ou, ainda, na p. 32: “há, em Murnau, justapostas, duas tendências opostas da pintura, em geral irreconciliáveis, e por ele quase conciliadas. De uma parte, o extremo rigor; de outra, a liberdade. Por um lado, o desejo de estilo; por outro, a paixão da realidade. Ser pintor não significa, para ele, em oposição a outros cineastas, a oportunidade de conjurar a maldição realista que pesa sobre a fotografia, de seguir em direção ao hieratismo e à abstração. A intensidade de vida coincide, ao contrário, em sua obra, com a intensidade pictórica. Para ele, a abstração, a deformação não são (como frequentemente crê Eisenstein) ponto de partida, mas de conclusão. A beleza dos momentos nos quais a realidade se sublima, transfigurando-se de si mesma, para elevar-se até a pintura, não é senão mais inelutável".

15. RICHTER, Hans. The film as an original art form. In: SITNEY, P. Adams (ed.). Film culture reader. Nova York: Cooper Square Press, 2000. p. 15, tradução minha.

16. Ibidem, p. 19, tradução minha. 


\section{0 espaço arquitetônico}

ano 17

n. 36

17. ROHMER, Éric. Le celluloïd et le marbre V: architecture d'apocalypse. Cahiers du cinéma, Paris, n. 53, p. 22-30, dez. 1955b. p. 24-25, tradução minha. Lembremos, a propósito, que Jean Cocteau dizia que um cineasta que enxerga a construção do próprio filme possui um "olho-arquiteto".

18. GOETHE, Johann Wolfgang von. Maximes et réflexions Paris: Brokhauss \& Avenarius, 1842. p. 172, tradução minha: “Um nobre filósofo disse que a arquitetura é uma música petrificada, e essa expressão deve ter excitado mais de um sorriso de incredulidade. Não acreditamos poder reproduzir melhor esse belo pensamento que ao chamarmos a arquitetura de uma música muda". Ele se referia, aqui, ao poeta alemão Novalis (1772-1801). 19. ROHMER, 1955b, p. 24 tradução minha.

20. Ibidem, loc. cit. Ver também a definição que the dá Alberti: "eu conferiria o estatuto de arquiteto àquele que souber, através de um método preciso e por vias admiráveis, tanto

conceber mentalmente quanto realizar tudo que, pelo deslocamento das massas, pela ligação e pela reunião dos corpos, servirá melhor aos mais nobres usos dos homens".

ALBERTI, Leon Battista. L'Art d'édifier. Paris: Seuil, 2004. p. 48, tradução minha.

21. ROHMER, 1991, p. 57 , tradução minha.

22. Ibidem, p. 58, tradução minha.

23. Cf. Ibidem, p. 75.
O segundo tipo de espaço no cinema, segundo Rohmer, é o que ele chama de arquitetônico, remetendo aos cenários, objetos e figurinos. De acordo com sua série de artigos publicados em 1955, "O celuloide e o mármore", encontramos na pintura, e mesmo no romance, o que ele denomina uma "tentação de arquitetura" ou, dito de outra forma, uma "visão arquitetônica da vida", ou seja, "uma perspectiva coerente na qual a estética tem a última palavra, ainda que a ética não se encontre totalmente ausente", presente na obra de pintores (como Lorrain, Carpaccio ou Poussin) que "tratam monumentos como se fossem paisagens, e paisagens como monumentos"17.

Ao contrário das outras artes que, segundo Rohmer, teriam por tarefa reproduzir ou cantar o mundo, a arquitetura (ou "música petrificada”, como preferia Goethe ${ }^{18}$ ) produz obras que integram o próprio mundo e "cuja ambição não é a de refazer a natureza, mas de enriquecê-la com aquisições novas" - o que, por outro lado, não significa abandonar "a estética do museu, para adotar a do cartão postal"19. E ainda que o cinema pertença à primeira dessas "categorias" - cuja tarefa seria, portanto, a de reproduzir o mundo -, Rohmer sustenta que, ao construir uma ficção a partir do próprio real (em segundo grau, contrariamente ao pintor), o cineasta seria antes um demiurgo que um criador - assim como a arquitetura em seu "reconhecimento de uma ordem"20.

Em sua tese, Rohmer começa definindo a arquitetura, de modo um tanto óbvio, como uma forma ou um conjunto de formas propostas ao olhar, ou seja, "forma de um edifício, forma de um objeto, forma de uma paisagem". Entretanto, ele acaba destacando que a especificidade da arquitetura é "o que ela tem de próprio, ou seja, sua “função”"21. Apesar de Fausto possuir um cenário desenvolvido sobretudo com um "interesse puramente decorativo" - já que "não é o cenário que determina o gesto, mas o gesto que, normalmente, nesse universo mágico, determina o cenário" -, os outros filmes de Murnau parecem, segundo Rohmer, beneficiar-se, ao contrário, de suas possíveis "virtudes funcionais", pois "os lugares não servem apenas de moldura para a ação, seu receptáculo; eles pesam sobre as atitudes dos personagens, influenciam sua atuação, ditam seus deslocamentos"22. Ele insiste que a importância do espaço arquitetônico não aparece na fase do roteiro, mas só se manifesta no exercício da mise en scène ${ }^{23}$. É somente a partir da articulação dos fragmentos de espaço com o tempo, e com o auxílio do espectador, que se esboça esse espaço no cinema, ainda assim, imaginário. 
Rohmer dedica um segundo aspecto desse espaço arquitetônico aos objetos. Ele chama a atenção para o fato de que eles servem, no cinema, como um tipo de compensação "imóvel” à mobilidade humana (ou animal) na tela. Mas se, por um lado, sua inércia pode servir ao ser animado como contraste ou padrão, por outro, seu eventual movimento - no caso de uma máquina, por exemplo - pode servir-lhe como auxiliar ou concorrente, ou mesmo como inimigo ${ }^{24}$. Assim, ele distingue os inúmeros objetos utilizados por Murnau em Fausto de acordo com duas categorias: os instrumentos - as ferramentas que os personagens empregam numa cena, exploradas por Murnau no nível dos "gestos que não levam a nada" - e os ornamentos - que não inspiram ação alguma, servindo apenas para ser admirados por sua própria beleza ${ }^{25}$.

O terceiro e último elemento que compõe o espaço arquitetônico diz respeito aos figurinos. Rohmer destaca, assim, nos filmes de Murnau, sobretudo a simplicidade extrema dos figurinos, em perfeita adequação aos cenários: "Fausto é sombrio em seu gabinete sombrio. Margarida é branca em seu quarto branco" ${ }^{26}$. Ele sustenta que esse gosto pelos tons unificados resulta de uma predominância da luz sobre o desenho: o que justifica que, num cenário bem iluminado, como a casa de Margarida, as roupas sejam não apenas unificadas, mas planas, evitando, desse modo, a sombra, e permitindo a difusão da luz; enquanto em um cenário contrastado, como o gabinete de Fausto, as dobras das vestimentas reproduzem a justaposição de sombra e claridade. Ele conclui que "num mundo feito de relações de força, não de persuasão", como o de Murnau, os figurinos - bem como os objetos nunca são vistos como um meio ou uma arma para seduzir, mas sobretudo para atacar ou se fazer atacar, num "universo de puro desejo" no qual "cada ser é para o outro um vampiro ou uma vítima" ${ }^{27}$. Rohmer também identifica essa metamorfose no Fausto, pois a mudança de figurino corresponde quase sempre a uma transformação profunda do ser. E afirma, ainda acerca de Murnau, que graças a seu temperamento de pintor, ele descobre os segredos das duas únicas maneiras nobres de se representar o modelo humano: o nu e o drapeado.

\section{0 espaço fílmico}

A terceira e última categoria de espaço cinematográfico proposta por Rohmer diz respeito ao que ele denomina espaço fílmico - relativo à decupagem e à montagem, mas também ao que ele chama de "jogo"28. É o espaço onde se harmonizam os "dois tipos de sujeito" que contribuem para a construção do filme: ou seja, de um lado, uma "dramaturgia das
Sobre a noção de três espaços no cinema

24. Cf. Ibidem, p. 76-77. E ele lembra que esse conflito entre homem e objeto num filme anima, particularmente, todo o cinema burlesco.

25. Ibidem, p. 78-79, tradução minha. No caso específico de Murnau, sobretudo em relação à luz, ficando "a léguas de distância dos preciosismos barrocos de Stroheim ou Sternberg [e] da bricolagem surrealista de Vigo ou Buñuel".

26. Ibidem, p. 84, tradução minha.

27. Ibidem, p. 84-87, tradução minha.

28. Vale ressaltar que a palavra que em francês designa "jogo" (jeu) possui numerosos significados, como: “atuação" (le jeu des acteurs), "representação teatral" lle jeu de la scènel etc.; assim como o verbo jouer serve tanto para "jogar", "brincar", quanto para "tocar" lum instrumento musical), "atuar" (no sentido teatrall etc. 
formas puras" (ou melhor dizendo, a forma do filme); de outro, um

ano 17

n. 36

29. Cf. ROHMER, 1991, p. 34 tradução minha.

30. Ibidem, p. 93-94, tradução minha.

31. Ibidem, p. 94, tradução minha. E ele acrescenta:

“Pode-se imaginar um filme 'decupado' no qual o tempo fílmico identifica-se com o tempo real do evento (por exemplo, uma reportagem com diferentes câmeras).

Por outro lado, teremos mais dificuldade em introduzir uma solução de continuidade temporal num espaço fílmico que coincide com o espaço real, ou seja, no qual o ponto de vista permaneça fixo. Nosso olho, de fato, tem dificuldade em reconhecer um raccord de um plano a outro".

32. Cf. Ibidem, p. 95-103, tradução minha.

33. Ibidem, p. 102, tradução minha.

34. Cf. Ibidem, p. 103-107, tradução minha: "0 trabalho de Murnau é de apropriação, não de eliminação, de decantação, como o de grande número de seus colegas, que parecem soprar atrás da marionete. Ele necessita do aporte pessoal de seus intérpretes, de sua carne, de sua natureza mais sedutora quando menos facilmente domável". drama no sentido corrente do termo, com sua temática e problemática (seu conteúdo ${ }^{29}$. Resumindo, não se trata mais de espaços estáticos nos quais se organizam os elementos e o seu entorno - e que ele associa, respectivamente, como vimos, à pintura e à arquitetura -, mas de um espaço dinâmico, em relação direta com o movimento, enquanto campo de exercício de dois tipos distintos de mobilidade: por um lado, a do motivo filmado, no interior do quadro; por outro lado, a da câmera, que muda de posição e, logo, de ponto de vista ${ }^{30}$.

Rohmer define a decupagem e a montagem - que ele considera, aliás, como sendo duas operações fundamentais da mise en scène cinematográfica - em termos de espaço, e não de tempo, pois "decupar e montar um filme é não apenas organizar sua duração, mas seu espaço" ${ }^{\text {31 }}$. Segundo ele, ao privilegiar as relações espaciais em detrimento das temporais, e a ação acontecendo, em vez de concluída, Murnau acaba empregando inúmeras elipses que não são, para ele, "senão um meio para chegar mais rápido ao essencial, para saltar por cima do tempo oco e dos espaços amorfos"32. E Rohmer complementa ainda que:

um plano de Murnau não se apresenta como a revelação de alguma coisa, mas como um campo aberto a essa revelação, fragmento de espaço vazio que o evento trata de fornecer (...) Resulta que o plano goza, em Murnau, de uma autonomia maior que em outras concepções cinematográficas. É ele próprio que nos ilumina, não seu confronto com aquele que o precede ou sucede. ${ }^{33}$

Vimos como Rohmer considera a decupagem e a montagem, em Murnau, sempre em relação com um tipo de movimento referente à câmera - como a panorâmica e o travelling no carrinho ou óptico (zoom). Mas existe um outro tipo de movimento no interior do plano, para ele ainda mais importante, denominado "movimento do motivo filmado" e associado, de modo mais geral, ao jogo dos atores. Ele analisa, assim, movimentos dos elementos naturais (a água, o ar e o fogo) nos filmes de Murnau, mas é aos movimentos dos atores que Rohmer dedica uma atenção especial, pois, a julgar pelos manuscritos do diretor alemão, parece que este controlava os mínimos movimentos de seus atores, bem como seu ritmo e sua inscrição no espaço ${ }^{34}$.

A respeito das direções privilegiadas de orientação do espaço em Murnau, Rohmer identifica três variações do movimento na construção fílmica: convergência/divergência, expansão/contração e atração/repulsão. Sobre a expansão, por exemplo, ele diz: 
os movimentos que Murnau ordena sabem (...) perturbar toda a extensão da imagem, como uma pedrinha na superfície da água límpida. Eles mobilizam não apenas uma zona mais ou menos grande da tela, mas sua superfície inteira, do centro às bordas e vice-versa. ${ }^{35}$

Apegado a uma tradição tipicamente francesa que privilegia, no cinema, uma construção eminentemente racional e narrativa, inspirada em grande parte no romance burguês do século XIX, Rohmer busca demonstrar, em sua análise do filme de Murnau, a centralidade do espaço na composição fílmica - assim como, a partir de outra tradição, anglo-americana, veremos autores como Peter Gidal e os cineastas do chamado Cinema Estrutural defenderem a predominância do tempo como elemento essencial do cinema ${ }^{36}$. Assim, mais do que servirem como categorias estanques e operacionais a serem adotadas ao se abordar um filme qualquer, as propostas analíticas de Rohmer apontam, antes, para os traços de uma determinada tradição ou perspectiva sobre o cinema atrelada a uma espécie de racionalização espacial do mundo, ao mesmo tempo que demonstram sua aptidão para abstrair da obra do cineasta alemão um pequeno tratado espacial do cinema, talvez mais alegórico e pedagógico do que produtivo, em sua dissecação de apenas um aspecto isolado do espaço-tempo complexo que compõe qualquer filme.

\section{Bibliografia}

ALBERTI, Leon Battista. L'Art d'édifier. Paris: Seuil, 2004.

BAZIN, André. Pintura e cinema. In: BAZIN, André. O que é o cinema? São Paulo: Cosac Naify, 2014. p. 205-210.

BRESSON, Robert. Notas sobre o cinematógrafo. São Paulo: Iluminuras, 2005.

GIDAL, Peter. Theory and definition of structural/materialist film. In: GIDAL, Peter (ed.). Structural film anthology. Londres: BFI, 1978. p. 1-21.

GOETHE, Johann Wolfgang von. Maximes et réflexions. Paris: Brokhauss \& Avenarius, 1842.

\section{Cristian Borges}

Sobre a noção de três espaços no cinema

35. Ibidem, p. 117-118, tradução minha.

36. Cf. GIDAL, Peter. Theory and definition of structural/ materialist film. In: GIDAL, Peter. Structural film anthology. Londres: BFI, 1978. p. 1-21. Nesse capítulo, o autor propõe, quase numa contraposição direta a Rohmer, três categorias de tempo no cinema lagradeço a Lucas Baptista por me apresentar esse textol. 
RICHTER, Hans. The film as an original art form. In: SITNEY, P. 2000. p. 15-20.

ROHMER, Éric. Le celluloïd et le marbre II: le siècle des peintres. Cahiers du cinéma, Paris, n. 49, p. 10-15, jul. 1955a.

ROHMER, Éric. Le celluloïd et le marbre V: architecture d'apocalypse. Cahiers du cinéma, Paris, n. 53, p. 22-30, dez. 1955b.

\section{ROHMER, Éric. L'Organisation de l'espace dans le Faust de Murnau. Paris: UGE, 1991.}

ROHMER, Éric. Le Goût de la beauté. Paris: Cahiers du cinéma: Éd. de l'Étoile, 1984.

SCHÉRER, Maurice. Le cinéma, art de l'espace. La Revue du cinéma, Paris, n. 14, p. 3-13, jun. 1948.

SORLIN, Pierre. Esthétiques de l'audiovisuel. Paris: Nathan, 1992.

Cristian Borges é professor do Departamento de Cinema, Rádio e Televisão e do Programa de Pós-Graduação em Meios e Processos Audiovisuais da Universidade de São Paulo (USP). Doutor em Cinema e Audiovisual pela Universidade Sorbonne Nouvelle Paris III e mestre em Cinema pela Universidade de Bristol (ambos com bolsa da Capes), foi pesquisador-visitante de pós-doutorado na Columbia University e na Tisch School of the Arts da New York University (com bolsa da Fapesp) e professor convidado na Universidad Iberoamericana do México. Cineasta, realizou sete curtas-metragens em cinco países e foi um dos fundadores do Festival Brasileiro de Cinema Universitário da Universidade Federal Fluminense (UFF). Organizou mostras e livros no Centro Cultural Banco do Brasil e na Cinemateca Brasileira sobre Agnès Varda, Alain Resnais, o Novo Cinema Independente Alemão e Harun Farocki. Diretor do Cinusp e membro da diretoria da Sociedade Brasileira de Estudos de Cinema e Audiovisual (Socine), é também vicecoordenador do Laboratório de Investigação e Crítica Audiovisual da USP (Laica). Nos últimos anos, tem se dedicado a pesquisas relacionadas ao movimento nas/das

Artigo recebido em 7 de abril de 2019 e aceito em 11 de junho de 2019. imagens e às relações entre cinema e dança, tendo realizado recentemente três curtasmetragens de dança com alunos do Curso Superior do Audiovisual da USP e bailarinos da São Paulo Companhia de Dança. 